\title{
Impacts of climate change on future flood damage on the river Meuse, with a distributed uncertainty analysis
}

\author{
S. Detrembleur ${ }^{1}$, F. Stilmant ${ }^{1}$, B. Dewals ${ }^{1}$, S. Erpicum ${ }^{1}$, P. Archambeau ${ }^{1}$ and M. Pirotton ${ }^{1}$ \\ ${ }^{1}$ Hydraulics in Environmental and Civil Engineering - University of Liège \\ Chemin des Chevreuils, 1 - 4000 Liège - Belgium \\ Email: michel.pirotton@ulg.ac.be
}

\begin{abstract}
Flood-risk assessments are an objective and quantitative basis for implementing harmonized flood mitigation policies at the basin scale. However, the generated results are subject to different sources of uncertainty arising from underlying assumptions, data availability and the random nature of the phenomenon. These sources of uncertainty are likely to bias conclusions because they are irregularly distributed in space. Therefore, this paper addresses the question of the influence of local features on the expected annual damage in different municipalities. Based on results generated in the frame of a transnational flood-risk-assessment project for the river Meuse (Western Europe) taking climate change into account, the paper presents an analysis of the relative contributions of different sources of uncertainty within one single administrative region (the Walloon region in Belgium, i.e. a river reach of approximately $150 \mathrm{~km}$ ). The main sources of uncertainty are not only found to vary both from one municipality to the other and in time, but also to induce opposite effects on the computed damage. Nevertheless, practical conclusions for policy-makers can still be drawn.
\end{abstract}

Keywords Floods, Risk analysis, Damage estimation, Climate change

\section{Introduction}

From 2009 to 2012, the four European countries affected by the floods of the river Meuse, i.e. France, Belgium, Germany and the Netherlands, joined in the transnational project AMICE ('Adaptation of the Meuse to the Impacts of Climate Evolution') in order to reach an agreement on the flood-risk mitigation policies that each country should implement in order to face climate change. The scientific component of this project was a joint basin-wide flood risk analysis, with future projections in the medium term (2020-2050) and in the long term (2070-2100) (Dewals and Fournier 2013).

The assessment of flood risk throughout Europe is based on rather heterogeneous and countryspecific methods, models and data sources (Becker et al. 2007, de Moel et al. 2009, Van Alphen et al. 2009, van Pelt and Swart 2011). However, the basins of European rivers like the Meuse do not necessarily remain within the borders of one single country. This is a challenge for flood risk analyses that aim at comparing the risk in different parts of one river basin (Becker et al. 2007, van Pelt and Swart 2011). In the AMICE project, the models in use in the four countries involved in the flood risk analysis were thus either homogenized (i.e. one single model was used throughout the whole study area - e.g. damage functions) or harmonized (i.e. inconsistencies between the models were removed e.g. boundary conditions of the different hydraulic models). The aim was to generate spatially consistent results despite the administrative borders.

From literature, it appears that the reliability of the results is a key issue in flood risk assessment, because such studies are commonly subject to significant uncertainties (Merz and Thieken 2009). Model validation can rarely be performed in a satisfactory manner, which leads authors to call for thorough uncertainty analyses as a means of circumscribing the reliability of the results (Merz and Thieken 2009, Merz et al. 2010). Examples of such uncertainty analyses that take into account different uncertainty sources and their contribution to the uncertainty on the results are given in literature (Apel et al. 2009, Merz and Thieken 2009, de Moel and Aerts 2011). However, the availability of data, rather than an objective basis, often determines the importance that is granted to the study of a given uncertainty source (Apel et al. 2009).

In a review article, Merz et al. (2010) point out that the relevance of the application of a given model to different locations is a question that deserves more attention, especially as existing studies on damage models show that their relevance for varying locations and/or times is limited. Merz et al. (2010) introduce the concept of area similarity as an indicator for the relevance of the transfer of damage models in space and time. For risk analyses covering large areas, this suggests that the sources 
of uncertainty might be irregularly distributed in space and time, and that comparisons might be biased, even in flood risk analyses that put an emphasis on the homogenization and/or harmonization of the models throughout the study area.

As a result, this paper starts from the AMICE results and applies a distributed sensitivity analysis that assesses the magnitude and origin of the uncertainty as a function of space and time. Results are only presented for the Walloon region of Belgium (i.e. a river reach of approximately $150 \mathrm{~km}$ ) in order to focus on a study area with limited heterogeneity (e.g. in which the same hydraulic model is applied). The aim is to highlight the effects of the heterogeneity of the uncertainty sources on the damage at the municipality scale.

\section{Study area and working hypotheses}

The river Meuse is a western European river that stretches over $905 \mathrm{~km}$ and whose approximately 34000-km² basin covers four countries: France (F), Belgium (B), Germany (D) and the Netherlands (NL). The highest discharges occur in winter and are due to general and long-lasting precipitations. de Wit et al. (2007a) divide the Meuse basin into three geological zones: from the spring (F) to Charleville-Mézières (F), from Charleville-Mézières to Liège $(B)$, and from Liège to the mouth (NL). In the upstream and downstream zones, the river is bordered by wide floodplains, whereas the Meuse valley is narrow and steep-sided in the central part, which has an important impact on the capacity for flood attenuation. Downstream of Charleville-Mézières, the river is completely regulated by mobile dams while there is only a partial regulation in the upstream zone.

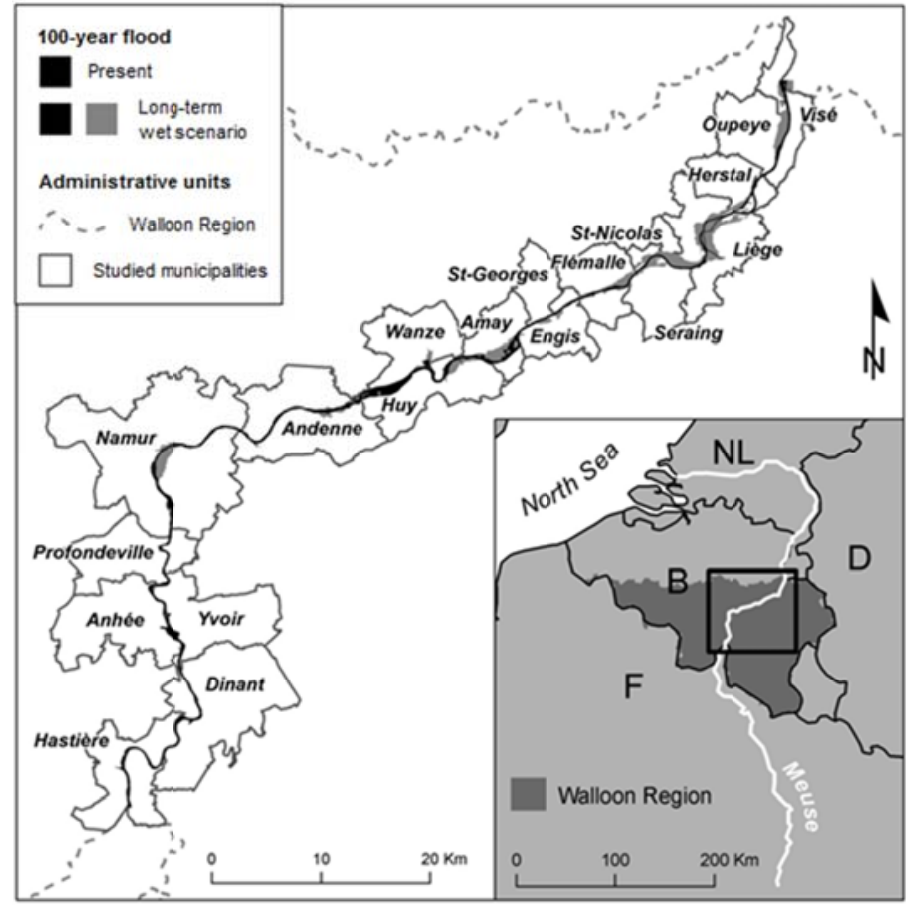

Fig. 1 Study area, Walloon reach of the river Meuse, with the nineteen municipalities (modified from Beckers et al., 2013)

Table 1 gives the boundaries, or working hypotheses, of the flood risk analysis presented in this paper. Flood hazard is described by the expected annual damage, which is the integral of the probability density function of the damage. Only direct tangible damage is considered. Indirect damage such as traffic interruption and intangible damage such as casualties are not taken into account, but they are generally considered as more difficult to assess than direct tangible damage. As a result, the study area is limited to the flooded area. 
Table 1 Boundaries of the flood risk analysis

\begin{tabular}{ll}
\hline Type of boundary & Description \\
\hline Damage & Direct tangible damage \\
& $\begin{array}{l}\text { Area defined by the inundation extent induced by the highest discharge }\left(\mathrm{Q}_{5}\right) \\
\text { in the Walloon reach of the river Meuse }\end{array}$ \\
Time & $\begin{array}{l}\text { Flood hazard in present situation and future projections in the medium term } \\
\text { (2020-2050) and in the long term (2070-2100) }\end{array}$ \\
& $\begin{array}{l}\text { Exposure and vulnerability in present situation (no evolution) } \\
\text { Ncenarios }\end{array}$ \\
& No failure of any flood protection \\
& No temporary installation of additional flood defense by emergency services \\
\hline
\end{tabular}

In comparison to the study area of the AMICE project, the area of interest of the study presented in this paper is limited to the nineteen Belgian municipalities of the Walloon stretch of the river Meuse, i.e. approximatively the central zone of the basin as described by de Wit et al. (2007a). The focus on municipalities within one single administrative unit helps removing the uncertainties induced by the use of different models. For instance the AMICE project did not impose the use of a single hydraulic model (Table 2), but paid attention to the correct interactions between the models in use in the different countries, i.e. a correct transfer of boundary conditions (discharges and water stages) from one model to the other. Moreover, the focus on a zone in which the morphological features of the basin are more or less homogeneous helps reducing the uncertainties induced by underlying assumptions. For instance, the assumption of no failure of flood protections has a different impact in the central zone of the Meuse basin region, where flood plains are small and flood protections mainly composed of concrete walls, and in the downstream zone, where flood plains are wide and flood protections mainly composed of dikes.

Table 2 State of the art in hydraulic modelling in the Meuse basin. Spatial discretization includes both onedimensional (1D) and two-dimensional (2D) models solving the complete shallow-water equations (SWE) or using storage cells. Either the entire flood wave (unsteady model) or its peak (steady model) is simulated.

\begin{tabular}{lclc}
\hline \multirow{2}{*}{ Country } & \multicolumn{2}{c}{ Spatial discretization } & \multirow{2}{*}{ Flood wave simulation } \\
\hline France (F) & Main stream & Flood plain & Unsteady \\
Belgium (B) & 1D (SWE) & 2D (storage cells) & \\
$\quad$ Wallonia (W) & 2D (SWE) & 2D (SWE) & Steady \\
Flanders (FL) & 1D (SWE) & 2D (storage cells) & Unsteady \\
The Netherlands (NL) & 1D (SWE) & 1D (SWE) & Unsteady \\
Germany (D) & 1D (SWE) & 2D (storage cells) & Unsteady \\
\hline
\end{tabular}

Only the evolution of the expected annual damage that is caused by an evolution in flood hazard is studied. No evolution in exposure or vulnerability is taken into account. For a thorough discussion on the relative influence of flood hazard evolution and exposure evolution in the same study area and the same long-term horizon (2100), we refer to Beckers et al. (2013), whose study includes a sensitivity analysis that considers several land-use evolution scenarios.

Finally, the working hypotheses regarding the flooding scenario consist in taking the situation as is. The failure of flood defenses is not modeled, nor is the intervention of emergency services.

All these working hypotheses restrict the scope of the study, but, in contrast, they help reducing the number of uncertainty sources and clarifying the discussion on the relative contributions of the remaining uncertainties.

\section{Data and methods}

The flood risk analysis follows a three-step procedure: flood frequency analysis, inundation estimation and damage estimation, as detailed in the subsequent sub-sections. As shown in Table 3, uncertainty arises at all steps of the analysis. In this study, the different sources of uncertainty are taken into account by using equivalent models to generate the results of a given step. Different model 
combinations in the procedure lead to different results, whose range give an indication of the magnitude of the total uncertainty.

Table 3 Uncertainty sources

\begin{tabular}{ll}
\hline Step in the analysis & Uncertainty sources \\
\hline Flood frequencies & Present situation: \\
& Statistical analysis \\
& Future projections: \\
& Emission scenario \\
& Global and regional climatic models \\
& Hydrological model \\
& Digital elevation model \\
Inundation estimation & Hydraulic model \\
& Boundary condition \\
& Roughness coefficient \\
& Steady-state assumption \\
& Exposure: \\
& Classification of elements at risk in homogeneous categories \\
Damage estimation & Localization of elements at risk \\
& Asset values \\
& Vulnerability: \\
& Damage influencing factors (e.g. velocities, duration) \\
& Stage-damage functions \\
\hline
\end{tabular}

\subsection{Flood frequency}

The discharges associated with a given return period in present situation have been derived from statistical analyses of the measurements at the gauging stations along the river Meuse. Such analyses have been made for each reach of the Meuse. The differences in the discharges between two successive stations have been attributed to the corresponding tributaries. Table 4 gives the obtained values upstream (Hastière) and downstream (Visé) of the study area. Note that the highest discharge measured in Chooz (upstream of Hastière) was 1575 m³ in January 1995 and that the highest discharge measured in Borgharen (downstream of Visé) was $3039 \mathrm{~m}^{3} / \mathrm{s}$ in December 1993 (de Wit et al. 2007a). In order to account for the uncertainty on the probability distributions of the discharges, return periods have also been assessed thanks to a Weibull distribution (Table 4).

The influence of climate change was modeled through a delta change approach in the medium term (2020-2050) and in the long term (2070-2100) (Dewals and Fournier 2013). National meteorological institutes derived seasonal increments in rainfalls and air temperature based on global/regional climate models forced with emission scenarios from the Intergovernmental Panel on Climate Change (IPCC 2000). According to several studies, dryer summers and wetter winters are expected in the Meuse basin (de Wit et al. 2007b, Leander et al. 2008). Nevertheless, even with wetter winters, not all models predict an increase in the extreme discharges (Leander et al. 2008). As a consequence, the AMICE project retained a 'dry' climate change scenario beside a 'wet' scenario, in order to take into account the wide range of predicted values. The 'wet' scenario leads to a basin-wide mean increase of the 100-year peak discharge by $15 \%$ in the medium term (2020-2050) and by 30\% in the long term (2070-2100). The 'dry' scenario leads to a slight decrease in the 100-year peak discharge. As a consequence, no distinction is made between discharges in the 'dry' scenario and discharges in the present situation (Table 4). 
Table 4 Expected evolution of the return periods of the five discharges taken into account in the study. Values are given for the dry scenario (DS) and the wet scenario (WS).

\begin{tabular}{ccccccccc}
\hline \multicolumn{3}{c}{ Discharge $\left(\mathrm{m}^{3} / \mathrm{s}\right)$} & \multicolumn{3}{c}{ Return period (years) } \\
$\mathrm{ID}$ & Hastière & Visé & \multicolumn{2}{c}{$\begin{array}{c}\text { Present \& DS } \\
\text { AMICE }\end{array}$} & $\begin{array}{c}\text { Medium term - WS } \\
\text { Weibull }\end{array}$ & AMICE & Weibull & \multicolumn{2}{c}{ AMICE } & Weibull \\
\hline $\mathrm{Q}_{1}$ & 1356 & 2726 & 25 & 23 & 10 & 12 & 5 & 8 \\
$\mathrm{Q}_{2}$ & 1501 & 2962 & 50 & 50 & 25 & 19 & 10 & 12 \\
$\mathrm{Q}_{3}$ & 1650 & 3150 & 100 & 100 & 40 & 29 & 25 & 17 \\
$\mathrm{Q}_{4}$ & 1898 & 3622 & 300 & 800 & 100 & 100 & 50 & 39 \\
$\mathrm{Q}_{5}$ & 2145 & 4095 & 1250 & 10000 & 250 & 430 & 100 & 100 \\
\hline
\end{tabular}

A risk assessment must ideally take all return periods into account to compute the expected annual damage, i.e. the integral of the probability density function of the damage. Practical limitations however hinder this. Messner et al. (2007) recommend a minimum of 3 to 6 return periods in the risk analysis. Penning-Rowsell et al. (2005) recommend a minimum of 5 return periods. Ward et al. (2011) showed that the use of a small number of return periods is an important source of uncertainty. Nevertheless, only a set of five return periods (25 to 1250 years in present situation) could be considered in this basin-wide analysis that involved a transnational modeling chain (Table 2). A sensitivity analysis of the results with respect to the number of return periods is presented in section 4.4.

\subsection{Inundation estimation}

The WOLF2D model, developed at the University of Liege, solves the complete two-dimensional shallow-water equations on a multibloc Cartesian grid ( $5 \mathrm{~m} \times 5 \mathrm{~m}$ in this case). Spatial discretization is based on a finite volume scheme, with mass and momentum fluxes being computed thanks to a fluxvector splitting method that enables consistent modeling of pressure and bottom slope terms. Time integration is achieved by means of an explicit Runge-Kutta algorithm constrained by a CourantFriedrich-Lewy stability criterion. Stability is also reinforced thanks to a semi-implicit treatment of the friction terms. A grid adaptation technique restricts the computation domain to the wet cells. Wetting and drying of cells is handled without any mass conservation error thanks to an iterative procedure (Erpicum et al. 2010a).

The digital elevation model is built on echo-sonar bathymetry and laser altimetry. Raw topographic data are corrected with field data in order to accurately take into account features like hydraulic structures and flood defenses. Roughness coefficients are spatially distributed and validated on historical flood events. They only stand for small scale friction because large scale roughness is taken into account in the digital elevation model (Ernst et al. 2010, Erpicum et al. 2010a).

The WOLF2D model is able to compute even highly transient flows (Erpicum et al. 2010b). Flood hazard mapping is however based on peak-discharge steady-flow simulations that run faster than unsteady simulations of the complete flood hydrograph. A high spatial resolution can thus be used within the extent of flooded areas ( $5 \mathrm{~m} \times 5 \mathrm{~m}$ in this study).

According to literature, hydraulic modeling is not the main source of uncertainty in a flood-risk assessment (Apel et al. 2009, Merz et al. 2010, Dottori et al. 2013). Uncertainty sources mainly arise from the digital elevation model, the underlying assumptions of the hydraulic model, and the boundary conditions (Table 3). The validation of the hydraulic model for inundation modeling along more than $1000 \mathrm{~km}$ of river reaches in the Walloon region has shown a mean absolute error on water stage values of 10 to $15 \mathrm{~cm}$ (Ernst et al. 2010, Erpicum et al. 2010a). In comparison with an unsteady simulation, the steady-state assumption induces an overestimation of the maximum water stages. In the study area, this overestimation is mostly not significant. However, for the most extreme discharge $\left(Q_{5}-\right.$ see Table 4), the overestimation reaches $20 \mathrm{~cm}$ in one reach, because of important flooding.

In order to account for the uncertainty in the inundation estimation, two types of results are used: the untreated steady-state water stages computed with the WOLF2D model, which are the reference values, and the same water stages decreased by $20 \mathrm{~cm}$, which show the influence of the uncertainty on the damage results. 


\subsection{Damage estimation}

\subsubsection{Exposure}

Damage assessment is made at a meso scale, i.e. at the scale of land-use units (Apel et al. 2009). In the AMICE project, the exposure model that defines the locations and monetary values of the possible elements at risk is based on the CORINE land cover data (CLC) and its classification. The 44 CLC categories are agglomerated into 5 damage categories: residential area, industry, infrastructure (e.g. roads), agriculture and forest.

CLC units have a minimum size of 25 ha. As such, they inevitably include heterogeneous elements among assets of the prevailing category, which have an influence on the mean monetary values attributed to the damage categories. In order to counterbalance this effect to some extent, the assessment of the asset values is based on a more precise land-use data source, available in vector format in the Walloon region (Computerized Localization Map, CLM). A comparison of CLC and CLM data is shown in Fig. 2. The Walloon Computerized Localization Map has more than 250 categories, belonging to 26 groups. However, for asset value estimation, these data are aggregated into 9 categories corresponding to the categories of the German ATKIS data set (Müller 2000), from which the mean monetary values are adapted (

Table 5). Mean monetary values for each of the 5 AMICE categories are then deduced from a weighted average of the mean monetary values of the 9 Walloon categories. Averaging is made within the present 100-year flood extent. Each value is weighted by the relative area occupied by the corresponding Walloon category within a given AMICE category. Results are given in

Table 5 and compared to the original data. This highlights the influence of the heterogeneity within CLC units on monetary values, which can change dramatically whether heterogeneity is taken into account or not. 
(a) AMICE damage categories - CORINE land cover

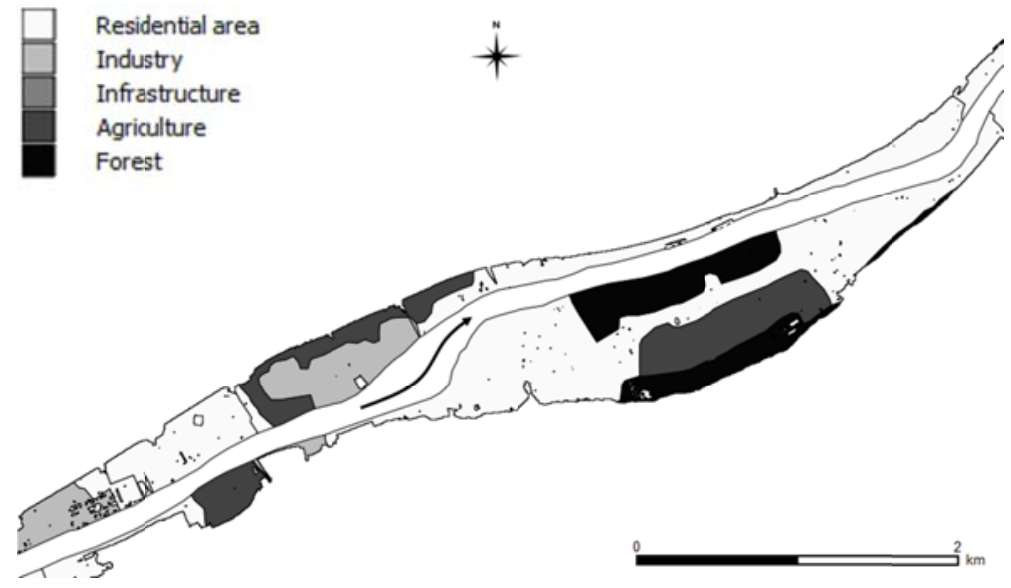

(b) ATKIS-derived damage categories - Walloon computerized localization map

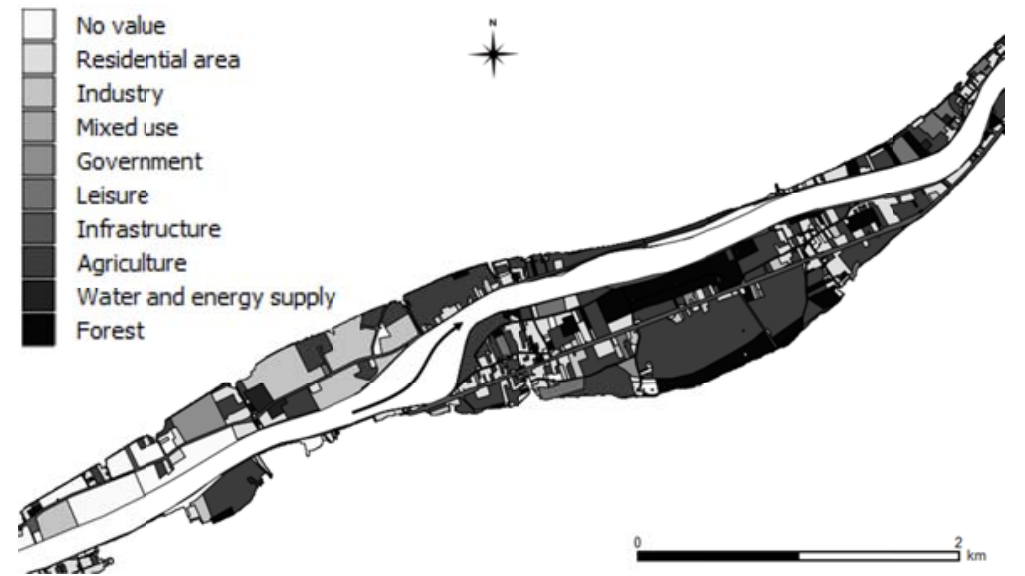

Fig. 2 Comparison of the two approaches used to define damage categories

Table 5 Damage categories and their mean monetary values in the Walloon region.

\begin{tabular}{|c|c|c|c|c|c|}
\hline \multicolumn{3}{|c|}{ AMICE categories } & \multicolumn{3}{|c|}{ ATKIS categories } \\
\hline \multirow{2}{*}{ Category } & \multicolumn{2}{|c|}{ Mean monetary value $\left(€ / \mathrm{m}^{2}\right)$} & \multirow{2}{*}{ Category } & \multicolumn{2}{|c|}{ Mean monetary value $\left(€ / \mathrm{m}^{2}\right)$} \\
\hline & Fixed asset & Moveable item & & Fixed asset & Moveable item \\
\hline \multirow[t]{4}{*}{ Residential area } & 172 & 112 & Residential area & 389 & 119 \\
\hline & & & Government & 370 & 1 \\
\hline & & & Mixed use & 655 & 131 \\
\hline & & & Leisure & 14 & 0 \\
\hline \multirow[t]{2}{*}{ Industry } & 192 & 98 & Industry & 343 & 119 \\
\hline & & & $\begin{array}{l}\text { Water and energy } \\
\text { supply }\end{array}$ & 392 & 3 \\
\hline Infrastructure & 137 & 211 & Infrastructure & 140 & 370 \\
\hline Agriculture & 50 & 24 & Agriculture & 3 & 0 \\
\hline Forest & 44 & 74 & Forest & 1 & 0 \\
\hline
\end{tabular}

In order to take into account the uncertainty induced by the classification of the elements at risk in homogeneous categories and their spatial localization, both damage categories are used in this study.

\subsubsection{Vulnerability}

The vulnerability model links flood hazard to relative flood-induced damage, which is defined as the percentage of the total value of an asset which is lost owing to a flood. A distinction is made between 
fixed assets (e.g. buildings) and moveable items (e.g. furniture, industrial equipment) because their vulnerability is different (Merz et al. 2010). Only water depths are taken into account in the damage function, even though other effects, like contamination of the flood water and people preparedness, are likely to play an important role (Apel et al. 2009, Merz and Thieken 2009). Velocities are not considered because the possibility of dike breaks is not taken into account in the scenarios (Deckers et al. 2010) and because water is almost standing in many flooded areas.

Fig. 3 shows the damage functions as defined in the AMICE project. They result from a homogenization procedure that takes into account the functions in use in all 4 countries. As a means of comparison, Fig. 3 gives the damage functions currently in use in the Walloon region, which are FLEMO curves (Thieken et al. 2005, Kreibich et al. 2007). The AMICE curves for residential areas and industries are quite similar. The comparison with the FLEMO curves shows that the trend for water depths higher than $\sim 2 \mathrm{~m}$ is very different. AMICE curves assume that a total damage is reached for water depths higher than $\sim 6 \mathrm{~m}$, whereas FLEMO curves assume that total damage is never reached.
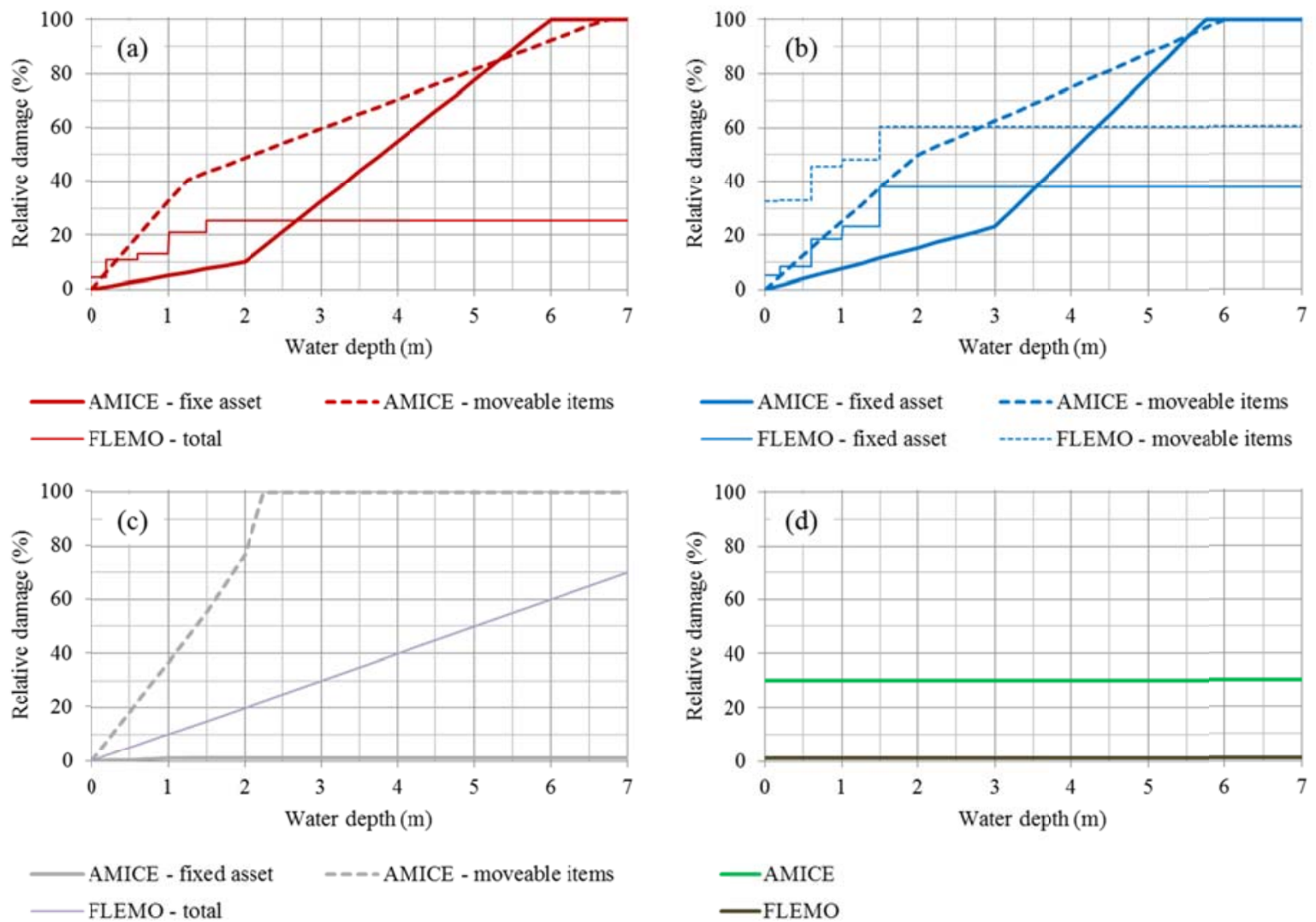

Fig. 3 AMICE and FLEMO stage-damage functions for (a) residential areas, (b) industry, (c) infrastructure, (d) agriculture and forest.

In order to account for the uncertainty induced by the vulnerability model, both sets of damage curves are used in this study.

\section{Results}

\subsection{Inundation extent}

The numerical simulations of the inundations induced by the set of five discharges presented in section 3.1 show that the origin of flood hazard evolves along the $150 \mathrm{~km}$ of the Walloon reach. According to Fig. 4, a distinction can be made between three groups of municipalities. From Hastière to Profondeville (group 1), flood hazard is mainly due to relatively frequent discharges $\left(\mathrm{Q}_{1}\right)$. The increment in inundation extent for higher discharges is relatively small ( $100 \%$ for $\left.\mathrm{Q}_{5}\right)$, which reflects the narrowness of the valley in this part of the reach. From Namur to Amay (group 2), the extents of the inundations induced by $\mathrm{Q}_{1}$ are the same order of magnitude as in group 1 . However, the increment 
induced by higher discharges is much more important ( 170 to $~ 1500 \%$ for $\mathrm{Q}_{5}$ ). Finally, from St.Georges to Visé (group 3), nearly no inundation occurs for discharges below $\mathrm{Q}_{3}$, which corresponds to the 100-yr discharge in present situation. Thus, flood hazard is only due to extreme events, which is an effect of the existence of flood protections (mainly concrete walls). In the municipalities of Seraing and Liège, the inundation that occurs for $\mathrm{Q}_{5}$ induces submersion depths that reach several meters in some zones, as a consequence of a subsidence process that has taken place over the past centuries due to mining operations.

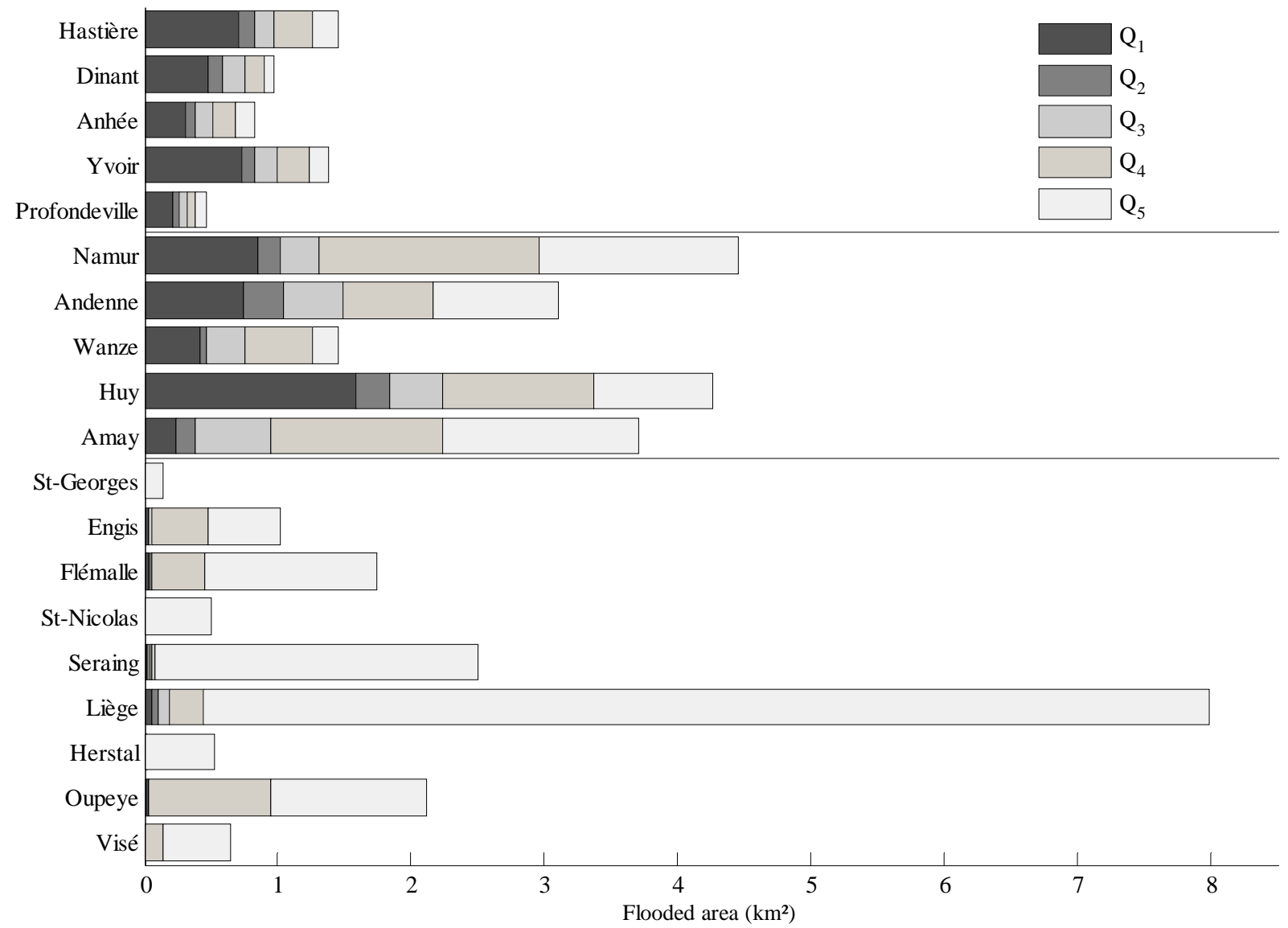

Fig. 4 Flooded areas per municipality, induced by the five discharges taken account in the study.

\subsection{Expected annual damage}

Fig. 5 shows the models used in the AMICE project together with the alternative models which have been considered as equivalent. There are 24 combinations that lead to 24 different results for each municipality. The best estimate is given by the choice of a particular model at a given step of the computation, or by the average of a set of models, as shown in Fig. 5 . The uncertainty range is given by the difference between the maximum and minimum value of all 24 results. 


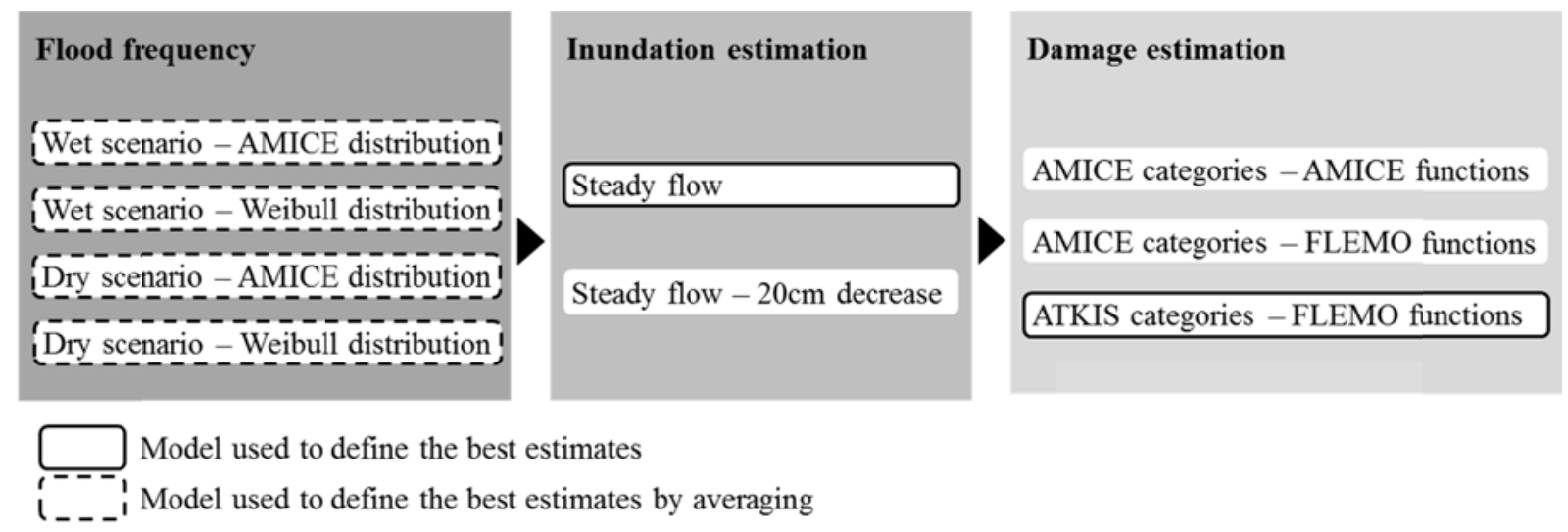

Fig. 5 Flow-chart of the three steps in the computation of the expected annual damage, with all alternatives.

(a)

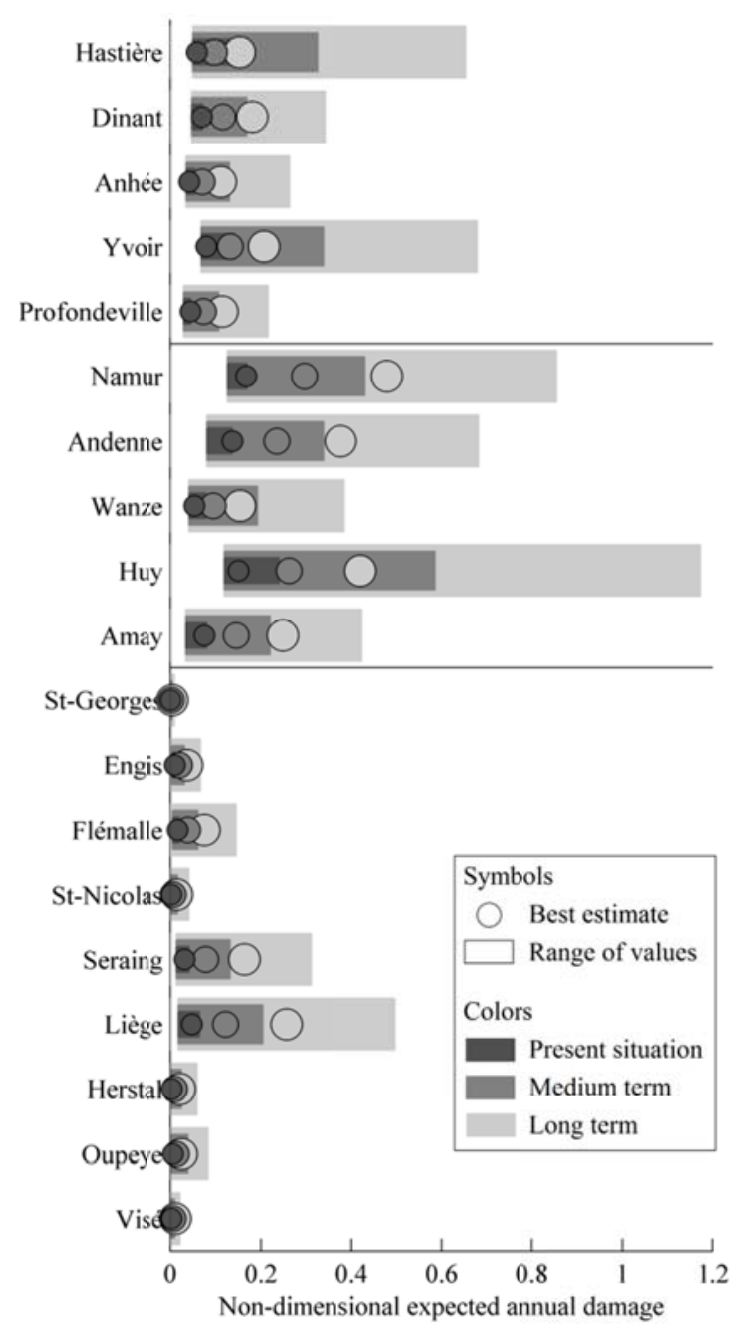

(b)

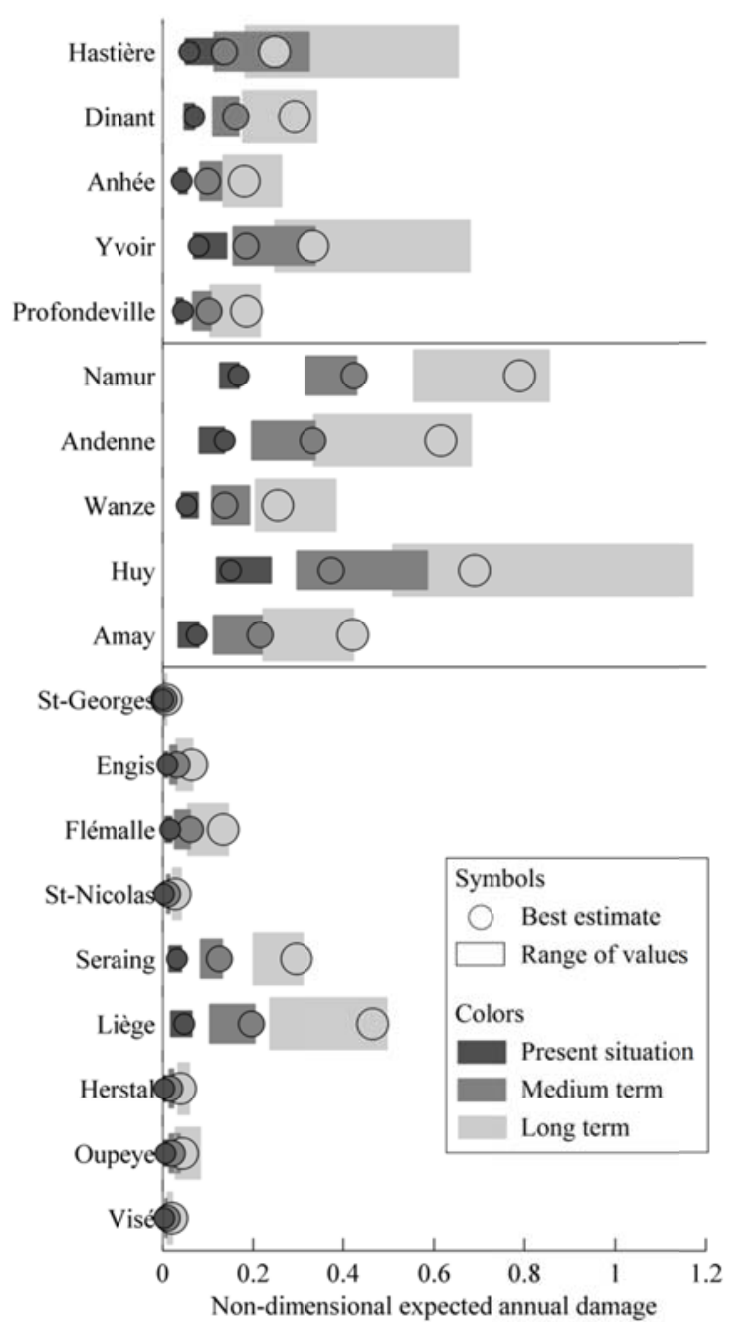

Fig. 6 Non-dimensional expected annual damage per municipality taking into account (a) both climate change scenarios, (b) only the wet scenario.

The expected annual damages per municipality are given in Fig. 6(a), with their best estimates and uncertainty ranges. All values have been normalized with respect to the best estimate of the total expected annual damage for all nineteen municipalities in present situation. 
The comparison of the best estimates of the damage for the different municipalities shows that the main trends are in accordance with the flood extents in Fig. 4. The highest expected annual damages are found in municipalities in which the flood hazard is mainly due to relatively frequent floods. In municipalities with flood protections against these relatively frequent floods, the expected annual damage is high only if the submersion depths for the most extreme discharges are dramatically high, as it is the case in Seraing and Liège, owing to mining subsidence.

The uncertainty ranges in Fig. 6(a) are rather important, and they increase with time in such a way that, in the long term, overlapping occurs for nearly all municipalities. As a consequence, it is no more possible to make an objective distinction between the municipalities, although such a distinction is expected to exist, as suggested by the best estimates. Nevertheless, as shown in Fig. 6(b), in the frame of one single climate change scenario, the uncertainty range is considerably reduced, and distinctions can be made between municipalities, even within the three groups defined in section 4.1.

The distribution of the uncertainty range with respect to the best estimate varies from one municipality to the other. For instance, in Fig. 6(b), the uncertainties on the damage in Yvoir tend to increase the value of the best estimate, while the uncertainties on the damage in Andenne tend to decrease the value of the best estimate. As a consequence, if the best estimates in Andenne are $\sim 1.8$ times higher than the best estimates in Yvoir, there is still a systematic overlapping of the uncertainty ranges.

\subsection{Contributions of uncertainty sources}

Uncertainties are associated with each of the three steps of the risk analysis, namely the estimation of flood frequency, inundation and damage. The relative contribution of each group of uncertainties is computed following the procedure defined by Visser et al. (2000) and (Merz and Thieken (2009)):

$$
R_{i}=\frac{\mathrm{MUR}-\mathrm{UR}_{i}}{\mathrm{MUR}}
$$

In Eqt. (1), $R_{i}$ is the relative contribution of step $i$ to the maximum uncertainty range MUR, and $\mathrm{UR}_{i}$ is the uncertainty range when only one alternative is considered for step $i$, i.e. the best estimate or the average which is supposed to give the best estimate, as defined in Fig. 5. Note that, with this definition, the sum of all three contributions is not necessarily equal to 1.

The results are given in Fig. 7 (for both climate change scenarios) and Fig. 8 (considering only the wet scenario). They show that, in present situation, the uncertainty associated with flood frequency has a negligible influence on the uncertainty of the expected annual damage in the municipalities from Hastière to Huy (i.e., the municipalities belonging to groups 1 and 2, as defined in section 4.1), while flood frequency estimation appears to be the main source of uncertainty in the municipalities from Flémalle to Herstal (i.e., municipalities belonging to group 3). As a consequence, a direct comparison of the expected annual damage between these two categories is delicate because the assumptions that have been made for the computation do not have the same influence in both areas.

According to Fig. 7, flood frequency is the main source of uncertainty in all municipalities in the medium and long term. The inundation estimation, despite the $20 \mathrm{~cm}$ variability accounted for in water stages, has a negligible influence on the results. In Fig. 8, in which results are given for the wet scenario only, the relative contributions of all three steps are less different in the medium and long term. The damage estimation is however the main source of uncertainty. In this case, the comparison of the expected annual damage from one municipality to the other suffers fewer critics due to heterogeneity of assumption implications. 

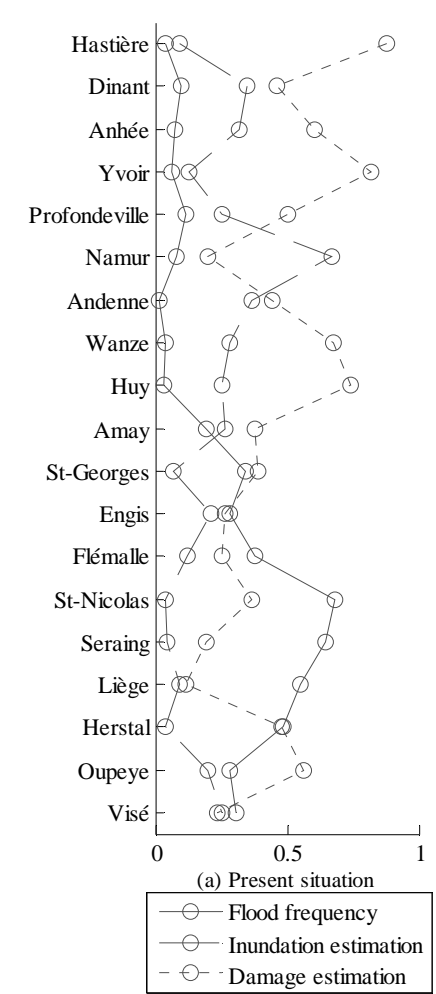

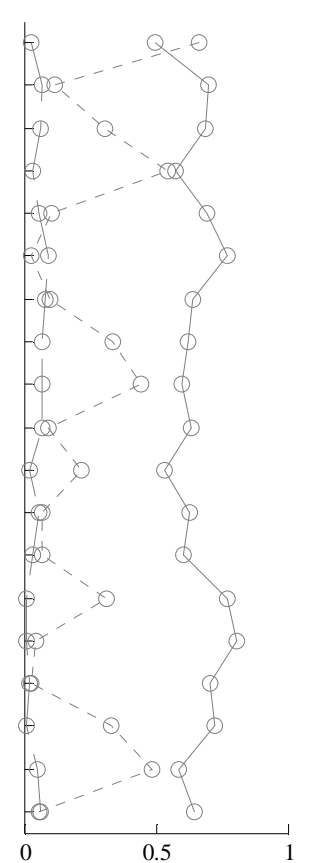

(b) Medium term

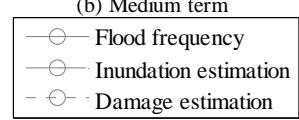

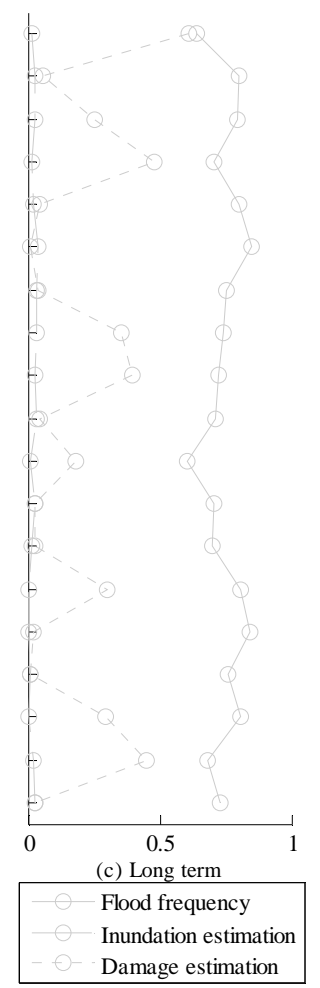

Fig. 7 Relative contributions of uncertainties in flood frequency, inundation and damage estimations to the total variability of the expected annual damage, when both climate change scenarios are taken into account.
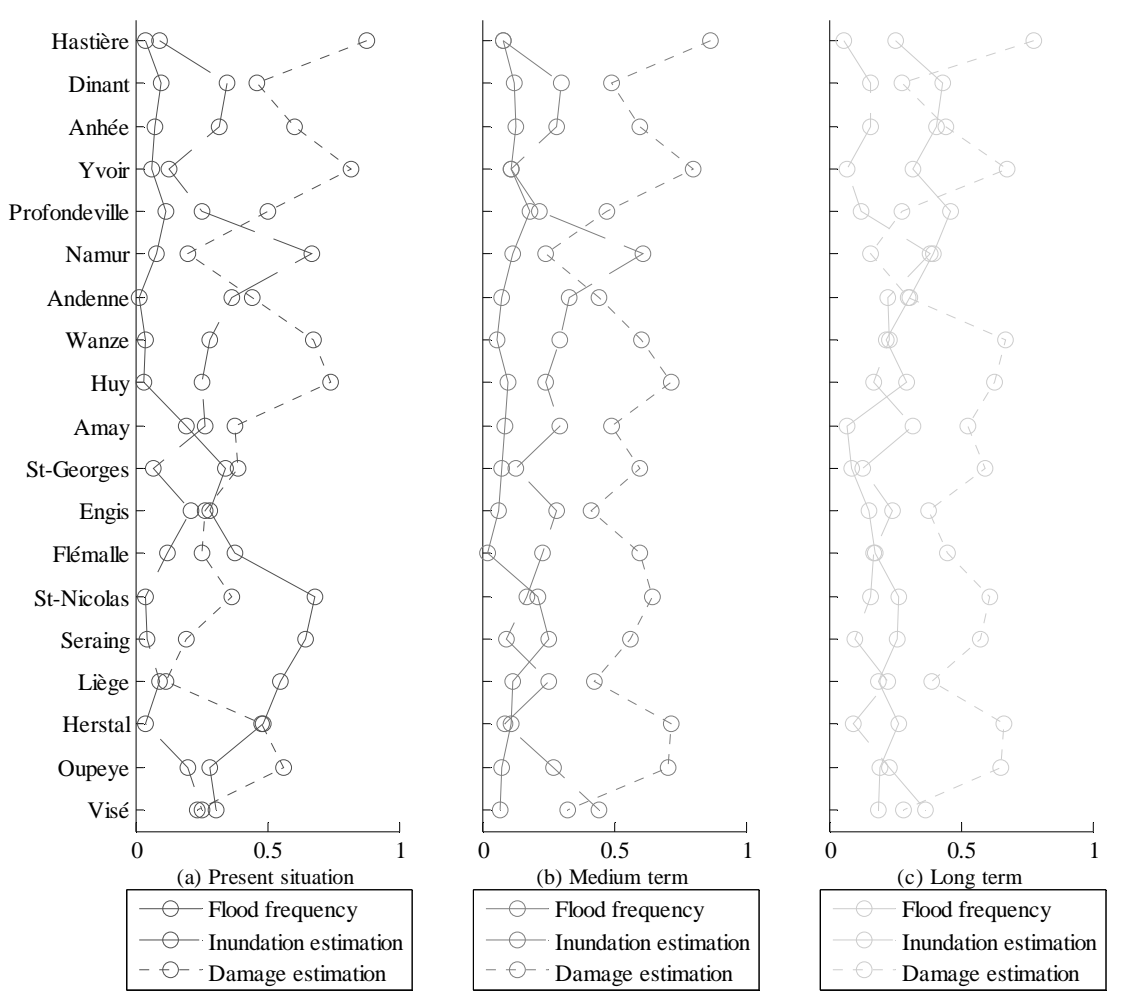

Fig. 8 Relative contributions of uncertainties in flood frequency, inundation and damage estimations to the total variability of the expected annual damage, when only the wet climate change scenario is taken into account.

\subsection{Sensitivity to the number of return periods}

The limited number of return periods taken into account in the analysis ( 5 values) has been identified as a source of error in section 3.1. The magnitude of this error is assessed in present situation by computing the expected annual damage with even less values, keeping the lowest $\left(\mathrm{Q}_{1}\right)$, middle $\left(\mathrm{Q}_{3}\right)$ 
and highest $\left(\mathrm{Q}_{5}\right)$ discharges only. This error assessment is based on the assumption that the convergence of the approximation of the integral of the damage probability density function is monotonic.

In all 19 municipalities, the use of three return periods instead of five induces an increase in the expected annual damage. The total increase in the whole study area is 33\% for present-situation values. However, as the focus of the risk analysis is put on relative values, the main question is whether the distribution of the expected annual damage is different. Fig. 9 shows that there is a difference between group 1 and group 2 municipalities (mainly a 15 to 20\% decrease) on one side and group 3 municipalities on the other side (an increase that can reach 110 to $180 \%$ ). This is due to an overestimation of the weight of extreme discharges in the approximation of the expected annual damage. As a result, the error on the number of return periods appears to attenuate the difference that exists between the damage in the municipalities where progressive flooding occurs and the municipalities where flooding is discontinuous.

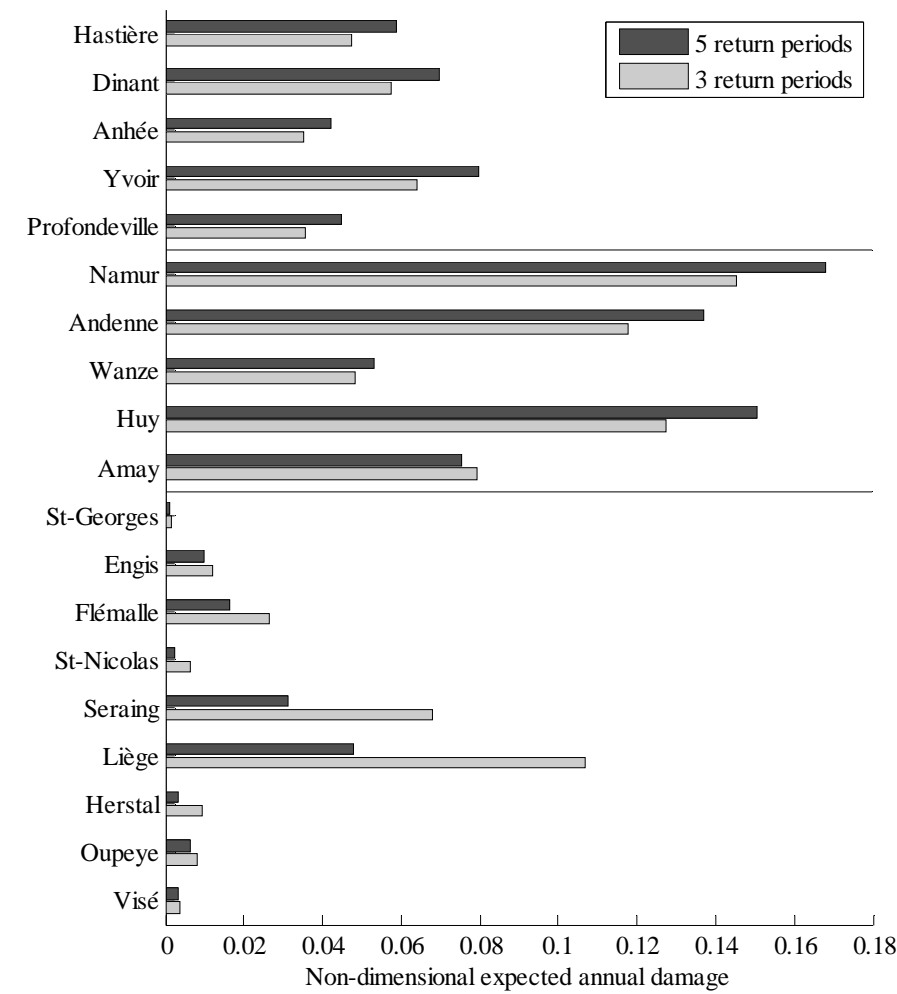

Fig. 9 Sensitivity of the non-dimensional expected annual damage with respect to the number of return periods taken into account in the approximation of the integral. The values correspond to the best estimates in present situation.

\section{Discussion}

The results presented in section 4 are hereafter compared to similar studies.

Merz and Thieken (2009) applied a flood risk analysis to the city of Cologne (river Rhine, Germany) and studied the uncertainty that originates from flood frequency, inundation estimation and damage estimation. The damage induced by a 100-year flood was found to vary from 1 to 5 due to the different sources of uncertainty. They computed the contribution of each step of the risk analysis to the total uncertainty for seven return periods (10, 20, 50, 100, 200, 500 and 1000 years). They found that the contribution of damage estimation was the lowest, with an almost constant value of 20 to $25 \%$ for all return periods. The main contribution to the total uncertainty was different at low ( $<100$ years) and high (> 100 years) return periods: in the first case, the main source of uncertainty was found to be the inundation estimation (contribution of about 60-70\%), while in the second case, flood frequency accounted for the main uncertainty (contribution of about 45-70\%).

Apel et al. (2009) assessed the damage induced in Eilenburg (river Mulde, tributary of the river Elbe, Germany) by the August 2002 flood and compared their values with the building repair costs as 
reported by the Saxonian Relief Bank. The different inundation and damage models they used gave a total damage that varied from 1 to 10. The application of Eqt. (1) to the results they report shows that the relative contribution of the inundation estimation to the total uncertainty range is $39 \%$ and that the contribution of the damage estimation is $92 \%$. These results are in accordance with the results of the study presented in this paper.

de Moel and Aerts (2011) assessed the damage of a flood induced by dike breaching in the Land van Heusden/Maaskant dike ring (the Netherlands). Results varied from 1 to 5-6. The inundation estimation was found to generate only limited uncertainties, even though water stages were decreased by $25 \mathrm{~cm}$. The damage estimation was found to be the main source of uncertainty, which was mainly due to the stage-damage curves and the asset values rather than the land-use maps.

\section{Conclusion}

This paper presents a distributed uncertainty analysis of the results of a flood risk analysis in the Walloon reach of the river Meuse. The uncertainties that have been studied are related to the three steps of the flood risk analysis, namely the flood frequency analysis, the inundation estimation and the damage estimation (exposure and vulnerability). The error generated by the use of a limited number of return periods in the assessment of the expected annual damage has also been analyzed. It appears that the magnitude of the uncertainty and its main origin vary, both in space and time. Moreover, uncertainty sources can have opposite effects on the damage computed in different municipalities. This has been related to local features, especially to how the floodplains inundate (progressive or discontinuous flooding). As a consequence, it appears that distributed uncertainty analyses are of prominent importance in order to show the spatial consistency of basin-wide damage assessments. Within the study area, this consistency appeared to be sufficient to draw conclusions at the municipality scale, provided that damages are compared for one single climate change model.

\section{References}

Apel, H., G.T. Aronica, H. Kreibich and A.H. Thieken (2009). Flood risk assessment - How detailed do we need to be? Natural Hazards 49(1): 79-98, doi:10.1007/s11069-008-9277-8.

Becker, G., J. Aerts and D. Huitema (2007). Transboundary flood management in the Rhine basin: challenges for improved cooperation. Water Science \& Technology 56(4): 125-135.

Beckers, A., B. Dewals, S. Erpicum, S. Dujardin, S. Detrembleur, J. Teller, M. Pirotton and P. Archambeau (2013). Contribution of land use changes to future flood damage along the river Meuse in the Walloon region. Nat. Hazards Earth Syst. Sci. 13(9): 2301-2318, doi:10.5194/nhess-13-2301-2013.

de Moel, H. and J.C.J.H. Aerts (2011). Effect of uncertainty in land use, damage models and inundation depth on flood damage estimates. Natural Hazards 58(1): 407-425, doi:10.1007/s11069-010-9675-6.

de Moel, H., J. van Alphen and J.C.J.H. Aerts (2009). Flood maps in Europe - methods, availability and use. Nat. Hazards Earth Syst. Sci. 9(2): 289-301, doi:10.5194/nhess-9-289-2009.

de Wit, M.J., H.A. Peeters, P.H. Gastaud, P. Dewil, K. Maeghe and J. Baumgart (2007a). Floods in the Meuse basin: Event descriptions and an international view on ongoing measures. International Journal of River Basin Management 5(4): 279-292.

de Wit, M.J.M., B. Hurk, P.M.M. Warmerdam, P.J.J.F. Torfs, E. Roulin and W.P.A. Deursen (2007b). Impact of climate change on low-flows in the river Meuse. Climatic Change 82(3-4): 351-372, doi:10.1007/s10584-006-9195-2.

Deckers, P., W. Kellens, J. Reyns, W. Vanneuville and P. Maeyer (2010). A GIS for Flood Risk Management in Flanders. Geospatial Techniques in Urban Hazard and Disaster Analysis. P. S. Showalter and Y. Lu, Springer Netherlands. 2: 51-69.

Dewals, B. and M. Fournier (2013). Transboundary Water Management in a Changing Climate. Leiden, The Netherlands, CRC Press/Balkema.

Dottori, F., G. Di Baldassarre and E. Todini (2013). Detailed data is welcome, but with a pinch of salt: Accuracy, precision, and uncertainty in flood inundation modeling. Water Resources Research 49(9): 6079-6085, doi:10.1002/wrcr.20406. 
Ernst, J., B. Dewals, S. Detrembleur, P. Archambeau, S. Erpicum and M. Pirotton (2010). Micro-scale flood risk analysis based on detailed 2D hydraulic modelling and high resolution geographic data. Natural Hazards 55(2): 181-209, doi:10.1007/s11069-010-9520-y.

Erpicum, S., B. Dewals, P. Archambeau, S. Detrembleur and M. Pirotton (2010a). Detailed inundation modelling using high resolution DEMs. Engineering Applications of Computational Fluid Mechanics 2(4): 196-208.

Erpicum, S., B. Dewals, P. Archambeau and M. Pirotton (2010b). Dam-break flow computation based on an efficient flux-vector splitting. Journal of Computational \& Applied Mathematics 234: 2143-2151, doi:10.1016/j.cam.2009.08.110.

IPCC (2000). Emissions Scenarios. UK, Cambridge University Press.

Kreibich, H., M. Müller, A.H. Thieken and B. Merz (2007). Flood precaution of companies and their ability to cope with the flood in August 2002 in Saxony, Germany. Water Resources Research 43(3): W03408, doi:10.1029/2005WR004691.

Leander, R., T.A. Buishand, B.J.J.M. van den Hurk and M.J. de Wit (2008). Estimated changes in flood quantiles of the river Meuse from resampling of regional climate model output. Journal of Hydrology 351: 331-343, doi:10.1016/j.jhydrol.2007.12.020.

Merz, B., H. Kreibich, R. Schwarze and A.H. Thieken (2010). Review article "Assessment of economic flood damage". Nat. Hazards Earth Syst. Sci. 10(8): 1697-1724, doi:10.5194/nhess10-1697-2010.

Merz, B. and A.H. Thieken (2009). Flood risk curves and uncertainty bounds. Natural Hazards 51: 437-458, doi:10.1007/s11069-009-9452-6.

Messner, F., E. Penning-Rowsell, C. Green, V. Meyer, S. Tunstall and A. van der Veen (2007). Evaluating flood damages: guidance and recommendations on principles and methods. FLOODsite Project deliverable D9.1.

Müller, W. (2000). ATKIS data base revision and generation of digital topographic base maps. International Archives of Photogrammetry and Remote Sensing 33: 710-717.

Penning-Rowsell, E., C. Johnson, S. Tunstall, S. Tapsell, J. Morris, J. Chatterton and C. Green (2005). The benefits of flood and coastal risk management: a handbook of assessment techniques. London, UK, Middlesex University Press.

Thieken, A.H., M. Müller, H. Kreibich and B. Merz (2005). Flood damage and influencing factors: New insights from the August 2002 flood in Germany. Water Resources Research 41(12): W12430, doi:10.1029/2005WR004177.

Van Alphen, J., F. Martini, R. Loat, R. Slomp and R. Passchier (2009). Flood risk mapping in Europe, experiences and best practices. Journal of Flood Risk Management 2(4): 285-292, doi:10.1111/j.1753-318X.2009.01045.X.

van Pelt, S.C. and R.J. Swart (2011). Climate Change Risk Management in Transnational River Basins: The Rhine. Water Resources Management 25(14): 3837-3861, doi:10.1007/s11269-0119891-1.

Visser, H., R.J.M. Folkert, J. Hoekstra and J.J. de Wolff (2000). Identifying key sources of uncertainty in climate change projections. Climatic Change 45(3-4): 421-457.

Ward, P.J., H. de Moel and J.C.J.H. Aerts (2011). How are flood risk estimates affected by the choice of return-periods? Nat. Hazards Earth Syst. Sci. 11(12): 3181-3195, doi:10.5194/nhess-113181-2011. 